\title{
Haemodynamics, exercise capacity and clinical events in pulmonary arterial hypertension
}

\author{
Gianluigi Savarese1, Francesca Musella1, Carmen D’Amore1, Teresa Losco', \\ Caterina Marciano', Paola Gargiulo', Giuseppe Rengo', Santo Dellegrottaglie ${ }^{1,2}$, \\ Eduardo Bossone ${ }^{3}$, Dario Leosco ${ }^{1}$ and Pasquale Perrone-Filardi ${ }^{1}$
}

Affiliations: 'Dept of Advanced Biomedical Sciences, Federico II University, Naples, ${ }^{2}$ Cardiology, Villa dei Fiori Hospital, Acerra, Naples, and ${ }^{3}$ Cardiology, Cava de' Tirreni and Amalfi Coast Hospital, Salerno, Italy.

Correspondence: P. Perrone-Filardi, Dept of Advanced Biomedical Sciences, Federico II University, Via Pansini, 5, I-80131 Naples, Italy. E-mail: fpperronđunina.it

ABSTRACT The purpose of this study was to clarify whether changes in cardiopulmonary haemodynamics induced by pharmacological therapy correlate with exercise capacity and clinical events in patients with pulmonary arterial hypertension.

16 randomised trials including 2353 patients, followed up for $16.4 \pm 10.6$ weeks, measuring cardiopulmonary haemodynamics by right heart catheterisation and reporting clinical events were included. Meta-analysis and meta-regression analysis were performed to assess the effects of treatments on clinical events and the relationship between haemodynamic changes (pulmonary artery pressure, pulmonary vascular resistance, cardiac index and right atrial pressure) and clinical events.

Treatments significantly reduced all-cause death (OR $0.5,95 \%$ CI $0.3-0.7 ; p<0.01$ ), hospitalisation for pulmonary arterial hypertension (OR $0.4,95 \%$ CI $0.2-0.7 ; \mathrm{p}<0.01$ ), initiation of rescue therapy (OR 0.3 , 95\% CI 0.2-0.6; $\mathrm{p}<0.01$ ) and the composite outcome (OR 0.3, 95\% CI 0.3-0.5; $\mathrm{p}<0.01$ ). No relationship was found between changes of haemodynamic parameters and clinical events, whereas changes of cardiac index and pulmonary vascular resistance significantly correlated with changes in the 6-min walking distance $(\mathrm{r}=0.64, \mathrm{p}=0.03 ; \mathrm{r}=-0.55, \mathrm{p}=0.04$, respectively).

In patients with pulmonary arterial hypertension, improvements of cardiopulmonary haemodynamics observed in randomised clinical trials correlate with exercise capacity changes but do not predict clinical events in a short-term follow-up.

@ERSpublications

In PAH, cardiopulmonary haemodynamic improvements correlate with exercise capacity changes but not with clinical events http://ow.ly/lzTdC

This article has supplementary material available from www.erj.ersjournals.com

Received: Aug 072012 | Accepted after revision: Sept 302012 | First published online: Oct 252012

Conflict of interest: None declared

Copyright @ERS 2013 


\section{Introduction}

Pulmonary arterial hypertension $(\mathrm{PAH})$ is a chronic syndrome characterised by progressive deterioration of cardiopulmonary haemodynamics and right ventricular function, leading to impaired exercise capacity and premature death [1].

Right heart catheterisation (RHC) is recommended by guidelines to measure cardiopulmonary haemodynamic parameters with the purpose of diagnosing PAH, defining its aetiology, guiding therapeutic management and obtaining prognostic information [2,3]. Yet, although the role of cardiopulmonary haemodynamic parameters is well recognised for the initial diagnostic workup, it is still uncertain whether changes of haemodynamics parameters reflect variations in the exercise capacity and in the incidence of subsequent clinical events in patients with PAH. In fact, although changes of cardiopulmonary haemodynamic parameters either represented the primary end-point [4-8] or were reported in several PAH randomised clinical trials [9-19], it has been not extensively investigated whether improvement of haemodynamic parameters correlates with improved exercise capacity. More importantly, the relationship of haemodynamic changes with major clinical events has never been assessed from randomised studies. However, this information is important for management of PAH patients to ultimately improve patient care.

Therefore, the aim of this meta-analysis was to investigate the relationship between changes of cardiopulmonary haemodynamic parameters induced by pharmacological therapies and exercise capacity, and clinical events in PAH patients enrolled in randomised clinical trials.

\section{Materials and methods}

Data sources and searches

The study was designed according to the PRISMA (Preferred Reporting Items for Systematic Reviews and Meta-Analyses) statement [20, 21]. The MEDLINE, Cochrane database, ISI Web of Science and SCOPUS database were searched for articles published in all languages until November 2011.

\section{Study selection}

Inclusion criteria were as follows. 1) Evaluation of cardiopulmonary haemodynamic by RHC at baseline and at end of follow-up; 2) report of clinical events (all-cause death, hospitalisation for PAH and/or lung or heart-lung transplantation, initiation of PAH rescue therapy); 3) comparison of active drug treatment versus placebo or of different doses of active drugs; and 4) randomised protocol design. Studies were identified using the major medical subject headings "pulmonary arterial hypertension", "randomised" and "haemodynamics". Hospitalisation was defined as end-point when it lasted at least $24 \mathrm{~h}$ and was determined by worsening of PAH clinical status. Rescue therapy was defined as interruption of blindness status of patients enrolled in clinical trials due to worsening clinical status.

\section{Data extraction and quality assessment}

Two reviewers independently screened articles according to fulfilment of inclusion criteria. Baseline characteristics, haemodynamic values (pulmonary artery pressure (PAP), pulmonary vascular resistance (PVR), right atrial pressure (Pra) and cardiac index) at baseline and end of follow-up, and clinical events were abstracted. A composite outcome including the above events was calculated and the assessment of the relationship between cardiopulmonary haemodynamic changes and composite outcome represented the first objective of the study. Additionally, the relationship between changes of haemodynamic parameters and changes of 6-min walking distance (6MWD) was also investigated. The quality of the trials was evaluated by Detsky's method [22], whereas publication bias was assessed using Macaskill's modified test [23].

Of 14906 articles identified by the initial search, 16 randomised trials including 2353 patients were included in the study (fig. 1). In 13 of these trials, including 1310 patients $[4-8,10,12-17,19]$, changes of $6 \mathrm{MWD}$ were also reported.

\section{Data synthesis and analysis}

Weighted random-effects meta-regression analysis was performed with the metareg command [24] (STATA version 11.0, StataCorps, College Station, TX, USA) to test the relationship between cardiopulmonary haemodynamic changes from baseline to end of follow-up and clinical events, as previously reported [25]. For this analysis, the achieved differences between cardiopulmonary haemodynamic changes in active treatment and control groups were considered $(\triangle \mathrm{PAP}, \Delta \mathrm{PVR}, \Delta \mathrm{Pra}$, and change in cardiac index $(\Delta \mathrm{CI})$ ). For all meta-regression analyses, a random-effects model was used. Tau ${ }^{2}$ and the restricted maximum likelihood (REML) methods were employed to explain residual heterogeneity not explained by potential effect modifiers [26]. To further explore the influence of the degree of haemodynamic changes on the relationship with clinical events, for each haemodynamic parameter, studies were divided in tertiles with the 


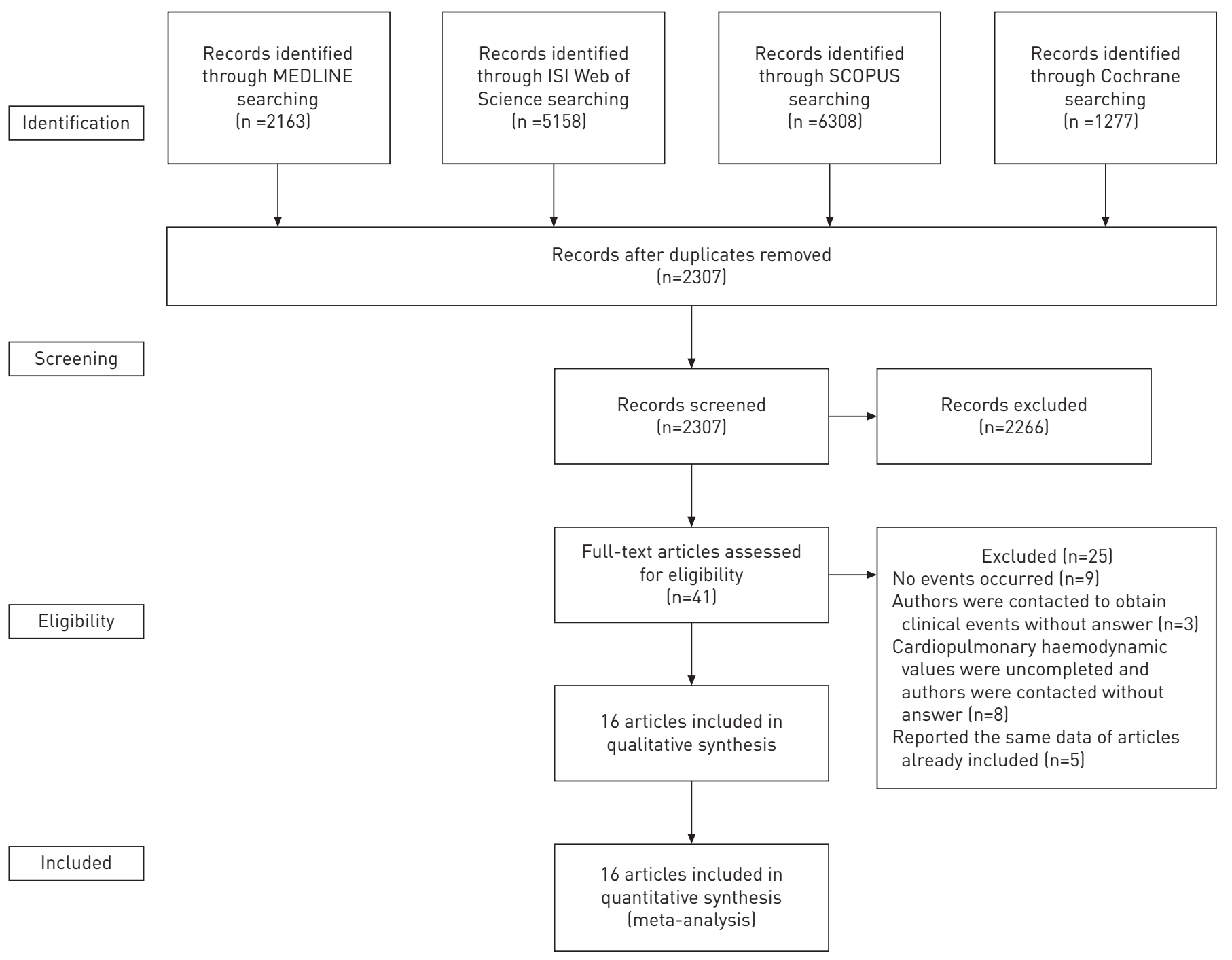

FIGURE 1 Meta-analysis flow chart.

first tertile including trials with the least favourable changes and the upper tertile including studies with the most favourable changes. Then, meta-regression was repeated, for each parameter, only for most favourable studies. Furthermore, the tertile $(1,2$ or 3$)$ to which each study belonged was tested as potential effect modifier in sensitivity analysis.

Unweighted Spearman correlation was used to test the relationship between changes in haemodynamics and changes in 6MWD.

\section{Outcome meta-analysis}

Odds ratios of the effect of treatments were calculated using the metan command (STATA, version 11.0; StataCorp, College Station, TX, USA) [27]. The choice to use odds ratio was driven by the retrospective design of the meta-analysis [27-29]. Overall estimates of effect were calculated with a fixed-effect model, random-effects model or Peto method as appropriate. Statistical homogeneity was assessed using Q and $\mathrm{I}^{2}$ statistics.

\section{Sensitivity analysis}

To assess the influence of potential effect modifiers on the association between haemodynamic changes and clinical events, meta-regression analyses were conducted, including the following variables as covariates, each separately: mean age, sex, race, type of $\mathrm{PAH}$, baseline functional class, changes in 6MWD $(\triangle 6 \mathrm{MWD})$ from baseline to the end of follow-up, Detsky quality score, duration of follow-up, study publication year, baseline haemodynamic parameters and tertile of haemodynamic changes. 


\section{Results}

Characteristics of included trials

Baseline characteristics of the 16 trials included in the study are reported in table 1. A total of 254 clinical events were reported in 2353 patients included in the meta-analysis. 385 patients were assigned to phosphodiesterase type 5 inhibitor inhibitors treatment, 942 to prostaglandin I 2 analogues, 300 to endothelin receptor antagonists, 28 to imatinib, 107 to conventional therapy and 1047 to placebo. Conventional therapy was defined as any combination of therapy including diuretics, anticoagulants and oxygen supply, but not including specific PAH drugs. Mean follow-up duration was $16.4 \pm 10.6$ weeks (range $8-52$ weeks). The overall mean age of patients was $44.4 \pm 5.9$ years and $76.5 \%$ were females.

\section{Effects of therapies on pulmonary haemodynamic parameters and exercise capacity}

Pooled weighted analysis of 16 trials reporting haemodynamic changes induced by active treatments showed a $12.7 \pm 6.4 \%$ increase of mean cardiac index, a $24.6 \pm 7.9 \%$ decrease of mean PVR, a $7.1 \pm 4.3 \%$ decrease of mean PAP and a $16.5 \pm 5.1 \%$ decrease of mean Pra. In 13 trials reporting exercise capacity, a $9.8 \pm 7.2 \%$ increase of mean $6 \mathrm{MWD}$ was observed.

A significant correlation was found between $\triangle 6 \mathrm{MWD}$ and $\Delta \mathrm{CI}(\mathrm{r}=0.6 ; \mathrm{p}=0.03)$ and between $\Delta 6 \mathrm{MWD}$ and $\Delta$ PVR $(\mathrm{r}=-0.55 ; \mathrm{p}=0.04)$, but not between $\Delta 6 \mathrm{MWD}$ and $\triangle \mathrm{PAP}(\mathrm{r}=0.74 ; \mathrm{p}=0.09)$ and between $\Delta 6 \mathrm{MWD}$ and $\Delta$ Pra $(\mathrm{r}=-0.57 ; \mathrm{p}=0.19)$ (fig. 2).

\section{Effects of therapies on outcomes}

Pharmacological treatments led to significant reduction of the composite outcome without heterogeneity among studies (OR $0.3,95 \%$ CI $0.3-0.5$, comparison $\mathrm{p}<0.01$, heterogeneity $\mathrm{p}=0.11$ ) (fig. 3). Additionally, each component of the composite outcome was significantly reduced by treatments, including all-cause death (OR $0.5,95 \%$ CI $0.3-0.7$, comparison $\mathrm{p}<0.01$, heterogeneity $\mathrm{p}=0.51$ ) (online supplementary fig. S1), hospitalisation for PAH and/or lung or heart-lung transplantation (OR 0.4, 95\% CI 0.2-0.7, comparison $\mathrm{p}<0.01$, heterogeneity $\mathrm{p}=0.82$ ) (online supplementary fig. S2) and initiation of PAH rescue therapy (OR $0.3,95 \%$ CI $0.2-0.6$, comparison $\mathrm{p}<0.01$, heterogeneity $\mathrm{p}=0.23$ ) (online supplementary fig. S3).

No relationship was found between $\triangle \mathrm{PAP}, \Delta \mathrm{PVR}, \Delta \mathrm{Pra}, \Delta \mathrm{CI}$ and the composite outcome by metaregression analysis. Additionally, no relationship was found between $\triangle \mathrm{PAP}, \triangle \mathrm{PVR}, \Delta P \mathrm{ra}, \Delta \mathrm{CI}$ and each component of the composite outcome (tables 2 and 3) (fig. 4) (online supplementary figs S4-S6). Furthermore, lack of association between each haemodynamic parameter and clinical events was also confirmed for trials belonging to the tertile with the most favourable response.

\section{Sensitivity analysis}

Results were confirmed when potential effect modifiers were introduced as covariates in the meta-regression analysis (online supplementary table S1).

\section{Publication bias}

No publication bias was detected by Macaskill's modified test for composite or single outcomes analysis.

\section{Discussion}

The main findings of the present analysis indicate that, in patients with $\mathrm{PAH}$, changes of haemodynamic cardiopulmonary parameters observed during short-term randomised clinical trials investigating pharmacological therapies correlate with changes of exercise capacity evaluated by 6MWD but not with clinical events. In particular, a significant direct correlation was found between cardiac index increase and $\triangle 6 \mathrm{MWD}$, whereas a significant inverse correlation was found between PVR decrease and $\triangle 6 \mathrm{MWD}$. However, no variation of any cardiopulmonary haemodynamic parameter correlated to clinical events occurrence during the short-term follow-up of clinical trials.

\section{Cardiopulmonary haemodynamic parameters in the management of PAH patients}

It has been observed in large registry studies that increased PAP and Pra, as well reduced cardiac index, are associated with worse prognosis in patients with PAH [30-34]. From these observations, survival equations have been developed that represent a useful tool to predict prognosis in PAH patients. Survival equations developed from the Registry to Evaluate Early and Long-Term Pulmonary Arterial Hypertension Disease Management (REVEAL) [31] and the French registry [33] include cardiopulmonary haemodynamic as well demographic and functional parameters, whereas in the Pulmonary Hypertension Correction equation, only cardiopulmonary haemodynamic parameters were significantly associated to prognosis [34]. Accordingly, several randomised trials in PAH have reported, as main [4-8] or secondary [9-19] endpoints, changes of cardiopulmonary haemodynamic parameters induced by specific PAH therapies. 


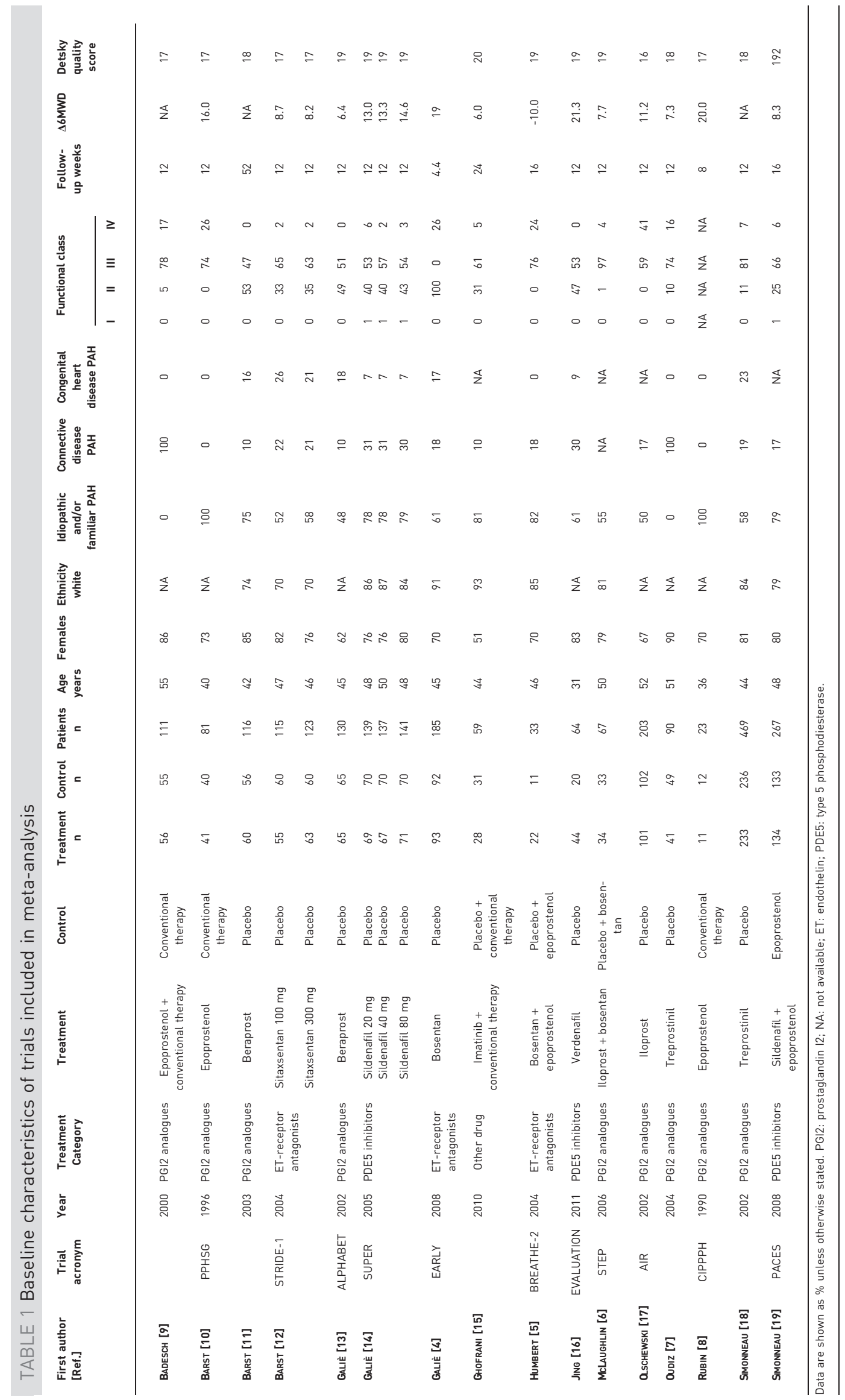



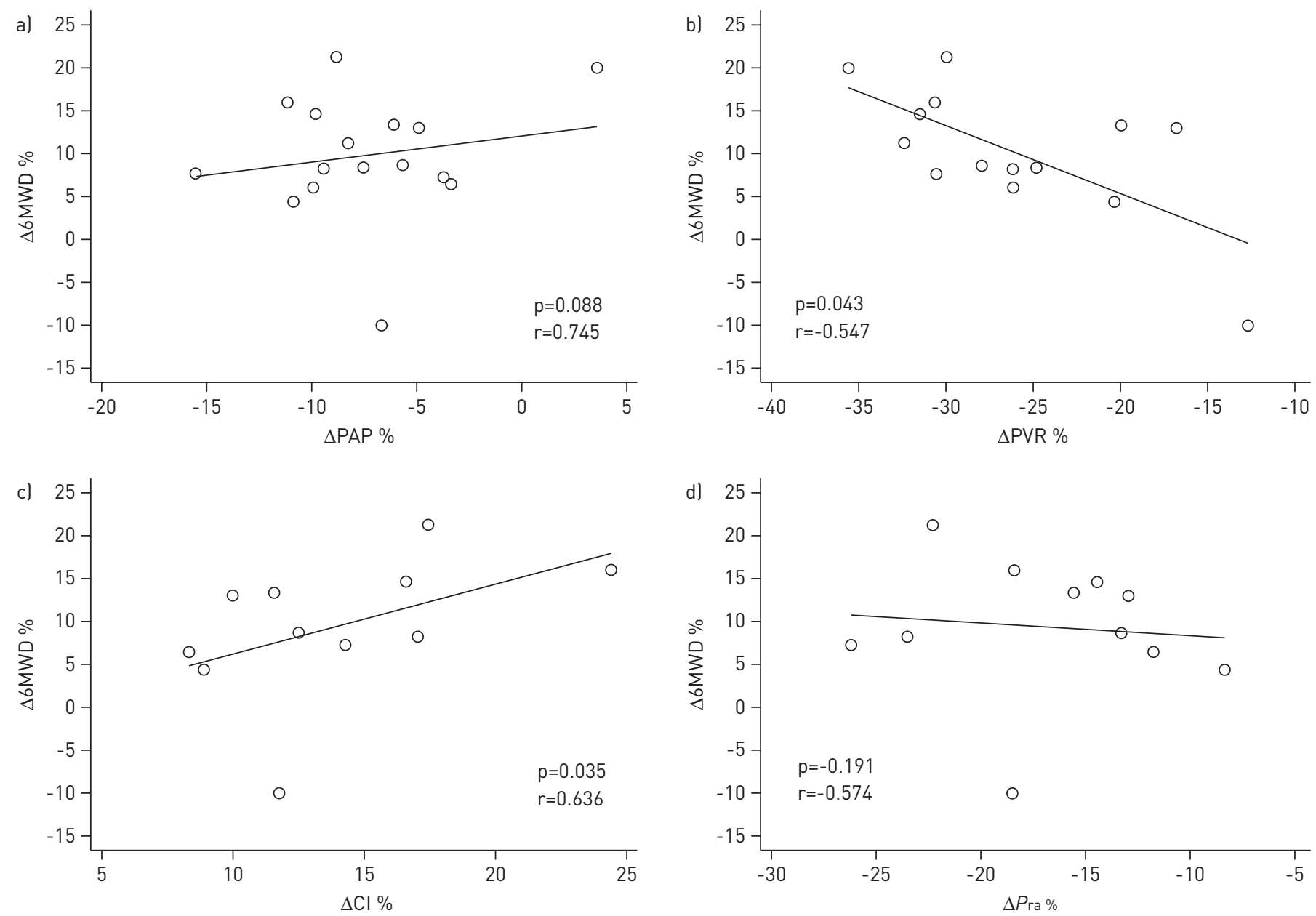

FIGURE 2 Linear regression between change in 6-min walking distance $(\triangle 6 \mathrm{MWD})$ and a) change in pulmonary arterial pressure ( $\triangle \mathrm{PAP})$, b) change in pulmonary vascular resistance $(\Delta \mathrm{PVR}), \mathrm{c})$ change in cardiac index $(\Delta \mathrm{CI})$, and $\mathrm{d})$ change in right atrial pressure $(\Delta P \mathrm{Pr})$.

However, the relationship between haemodynamic changes and either changes of exercise capacity or occurrence of clinical events is still unclear, leading the European Society of Cardiology and the European Respiratory Society to consider repeat of RHC after initiation of therapy or, in thr case of clinical deterioration as class II recommendation, with level of evidence C [2], whereas no clear indication for repeating invasive measurement of cardiopulmonary haemodynamic is made by the American College of Cardiology and American Heart Association guidelines on PAH [3].

\section{Cardiopulmonary haemodynamic changes and exercise capacity in PAH}

In the current study, a significant association was found by regression analysis between cardiopulmonary haemodynamic changes and exercise capacity, evaluated by the 6MWD test. In particular, the $\Delta 6 \mathrm{MWD}$ directly correlated with cardiac index increase and inversely correlated with $\triangle$ PVR. Although both haemodynamic and exercise changes were concomitantly assessed in 13 randomised trials [4-8, 10, 12-17, 19], to our knowledge, only BARST et al. [10], in their pivotal epoprostenol study, investigated the correlation between haemodynamic and exercise parameters. In agreement with our meta-analysis, they also found a significant association between haemodynamic changes and improvement of 6MWD whereas, at variance with our study, they also reported in 81 patients analysed, a significant association between change in 6MWD and change in mean PAP and change in mean Pra. Thus, our aggregate results, in agreement with those of BARST et al [10] from a single clinical trial, indicate that haemodynamic improvement induced by vasodilator therapies in PAH plays a relevant role in the amelioration of exercise capacity.

\section{Cardiopulmonary haemodynamic changes and short-term mortality/morbidity in PAH patients}

The relationship between haemodynamic changes and clinical events has been investigated in nonrandomised studies [35-37] indicating that improvement of cardiac index and PAP [36] and decrease 


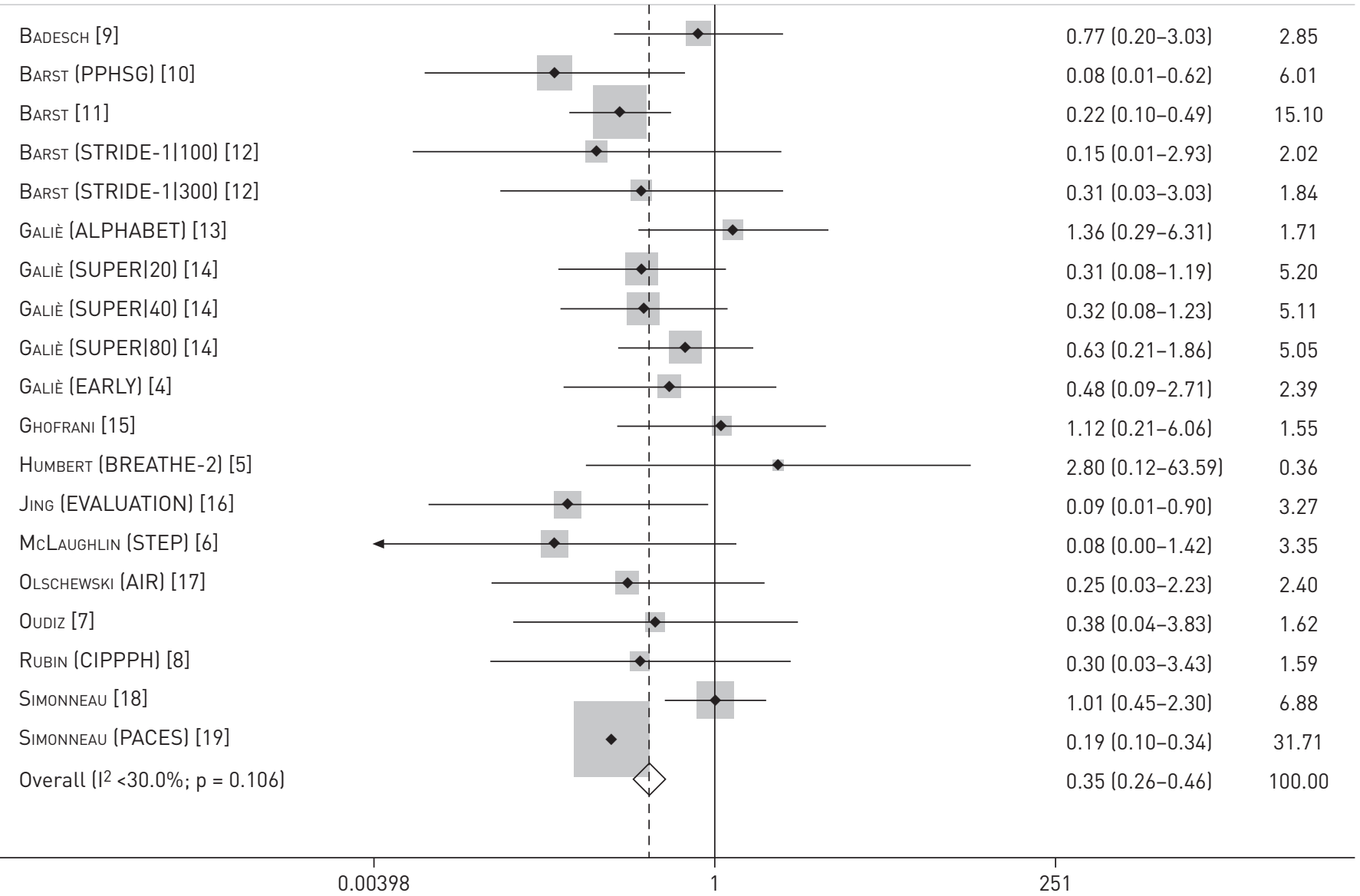

FIGURE 3 Odds ratio (OR) estimate of composite outcome in active treatment groups compared with control groups.

or no changes of PVR [35, 37] are associated with long-term clinical outcome in PAH patients. More recently, an analysis of patients undergoing subcutaneous treprostinil therapy followed up for 3 years, also reported that on-treatment changes of mixed oxygen venous saturation and of 6MWD predicted survival in PAH patients [38], whereas NICKEL et al. [39] showed that changes of mixed oxygen venous saturation and cardiac index predicted survival over a 38-month follow-up in 109 patients with PAH.

The association between cardiopulmonary haemodynamic changes observed during randomised clinical studies and occurrence of clinical events using has never been systematically evaluated. The results of our meta-regression analysis indicate that no statistically significant association exists between pulmonary haemodynamic changes and clinical events occurring during the short-term follow-up of randomised studies. Explanation for the lack of correlation between haemodynamic improvement and events, and the reasons for the apparent discrepancy with observational nonrandomised studies, can only be hypothesised. It has been suggested that parameters reflecting right ventricular function are more predictive of clinical outcomes compared with cardiopulmonary haemodynamic changes. In a recent study, VAN DE VEERDONK et al. [40] observed that right ventricular function, evaluated by magnetic resonance imaging, deteriorated in a subgroup of a population of 110 patients with treated PAH, despite reduction of PVR, and that in these patients, prognosis was poor irrespective of PVR changes. Thus, it is conceivable that improvement of haemodynamic parameters induced by therapies may occur despite deterioration or no changes in right ventricular function, thus correlating in the short-term with exercise capacity but not with clinical events $[41,42]$. In fact, consistent with the current findings, in a recent meta-analysis exercise capacity changes reflected by 6MWD test in PAH did not correlate with clinical events [43].

Despite potential pathophysiological explanations, the lack of association between haemodynamic changes and events observed in our study must be interpreted with caution and not as evidence of uselessness of haemodynamic monitoring in PAH patients, for several considerations. First, our findings are restricted to 


\begin{tabular}{|c|c|c|c|c|c|c|}
\hline Outcome & $\operatorname{Exp}(B)$ & SE & $95 \% \mathrm{Cl}$ & $\begin{array}{l}\text { Change } \\
\text { in } \mathrm{Tau}^{2}\end{array}$ & $\begin{array}{l}p \text {-value } \\
\text { for Tau }\end{array}$ & REML \\
\hline \multicolumn{7}{|l|}{$\triangle \mathrm{PAP}$} \\
\hline All-causes death & -0.32 & 0.67 & $-0.18-0.11$ & -0.48 & 0.64 & 0.00 \\
\hline Hospitalisation for $\mathrm{PAH}$ and/or lung or heart-lung transplantation & 0.07 & 0.13 & $-0.23-0.37$ & 0.55 & 0.60 & 0.07 \\
\hline Initiation of PAH rescue therapy & -0.01 & 0.13 & $-0.32-0.30$ & -0.07 & 0.94 & 0.64 \\
\hline Composite outcome & 0.01 & 0.06 & $-0.11-0.14$ & 0.20 & 0.84 & 0.28 \\
\hline \multicolumn{7}{|l|}{$\triangle P V R$} \\
\hline All-causes death & 0.03 & 0.03 & $-0.04-0.09$ & 0.90 & 0.39 & 0.00 \\
\hline Hospitalisation for PAH and/or lung or heart-lung transplantation & 0.00 & 0.06 & $-0.14-0.15$ & 0.07 & 0.95 & 0.09 \\
\hline Initiation of PAH rescue therapy & 0.05 & 0.09 & $-0.19-0.28$ & 0.51 & 0.63 & 0.75 \\
\hline Composite outcome & 0.02 & 0.03 & $-0.05-0.09$ & 0.62 & 0.54 & 0.28 \\
\hline \multicolumn{7}{|l|}{$\Delta \mathrm{Cl}$} \\
\hline All-causes death & -0.03 & 0.04 & $-0.12-0.06$ & -0.83 & 0.43 & 0.00 \\
\hline Hospitalisation for $\mathrm{PAH}$ and/or lung or heart-lung transplantation & 0.01 & 0.08 & $-0.19-0.22$ & 0.16 & 0.88 & 0.00 \\
\hline Initiation of PAH rescue therapy & -0.07 & 0.12 & $-0.45-0.30$ & -0.61 & 0.59 & 0.00 \\
\hline Composite outcome & -0.03 & 0.03 & $-0.11-0.04$ & -1.02 & 0.33 & 0.07 \\
\hline \multicolumn{7}{|l|}{$\Delta$ Pra } \\
\hline All-causes death & 0.01 & 0.07 & $0.15-0.17$ & 0.18 & 0.86 & 0.00 \\
\hline Hospitalisation for PAH and/or lung or heart-lung transplantation & 0.00 & 0.11 & $-0.27-0.28$ & 0.05 & 0.96 & 0.00 \\
\hline Initiation of $\mathrm{PAH}$ rescue therapy & -0.08 & 0.12 & $-0.40-0.25$ & -0.67 & 0.54 & 0.291 \\
\hline Composite outcome & -0.01 & 0.55 & $-0.13-0.11$ & -0.14 & 0.89 & 0.220 \\
\hline
\end{tabular}

Exp(B): exponential value of B coefficient; REML: restricted maximum likelihood; $\triangle \mathrm{PAP}$ : change in pulmonary arterial pressure; PAH: pulmonary arterial hypertension; $\triangle \mathrm{PVR}$ : change in pulmonary vascular resistance; $\Delta \mathrm{Cl}$ : change in cardiac index; $\Delta$ Pra: change in arterial pressure.

randomised clinical trials and to the short period of observation, usually 3-4 months, commonly covered in these trials. This is quite a relevant aspect because, as outlined by MiLLer et al. [44], clinical trials usually include stable patients with potential survival bias, for whom a short-term period of observation may prevent the occurrence of a number of events statistically adequate to be tested for association with haemodynamic changes. In addition, randomised studies include different type of drugs and different

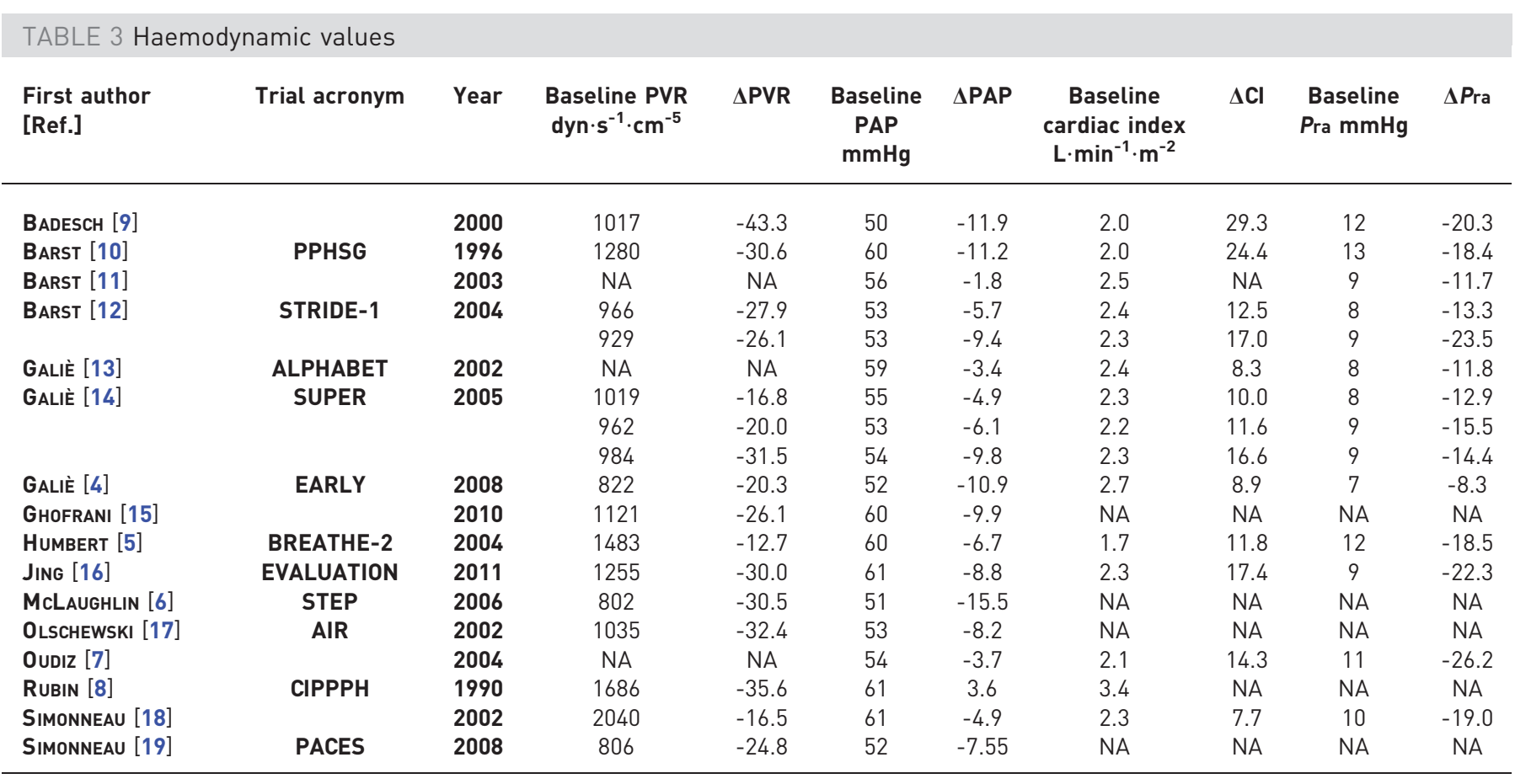

Data are presented as \% unless otherwise stated. PVR: pulmonary vascular resistance; $\triangle \mathrm{PVR}$ : change in PVR; PAP: pulmonary arterial pressure; $\triangle \mathrm{PAP}$ : change in PAP; Pra: right atrial pressure; $\triangle$ Pra: change in Pra; NA: not available. 

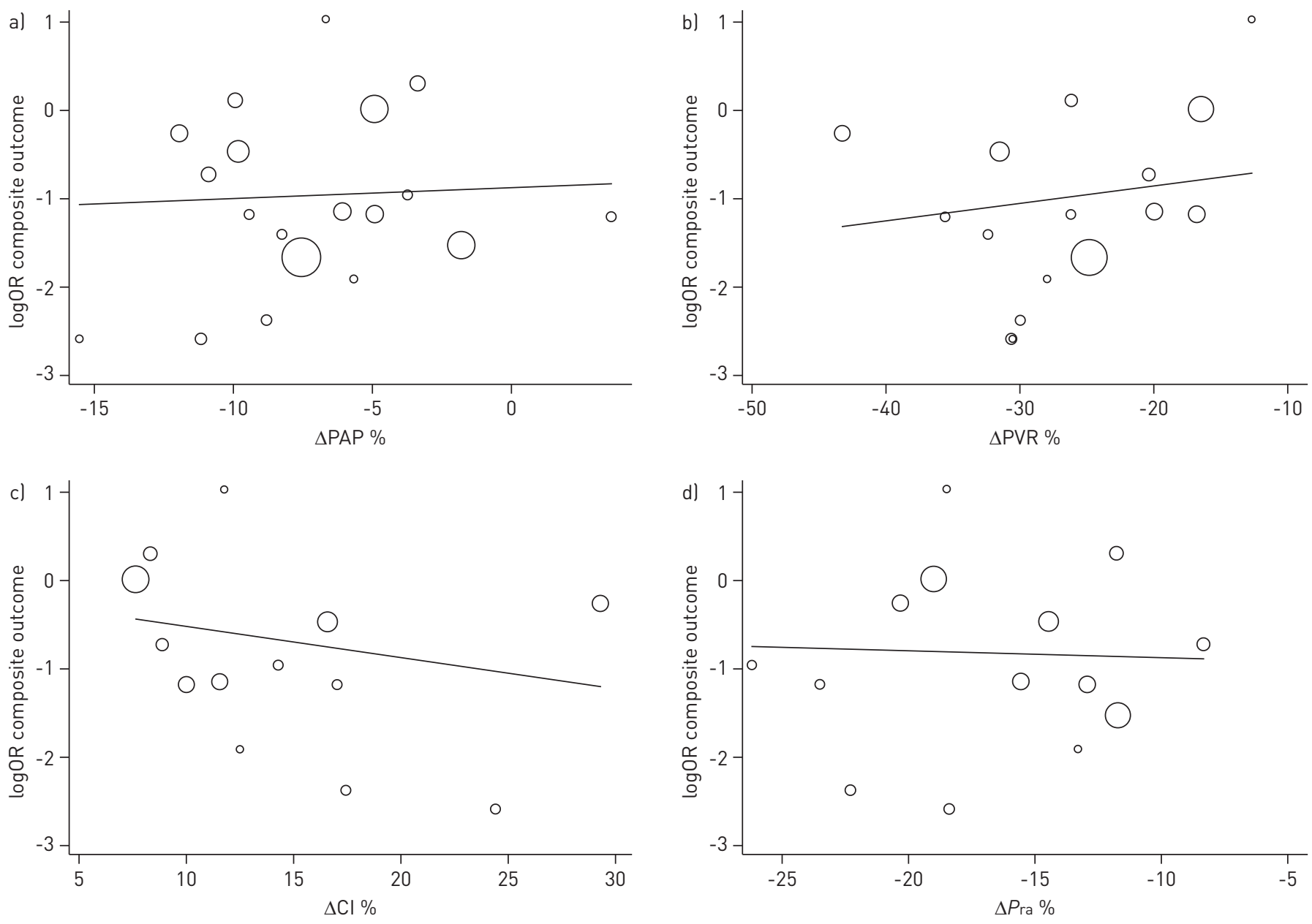

FIGURE 4 Meta-regression between composite outcome and a) change in pulmonary arterial pressure ( $\Delta \mathrm{PAP})$, b) change in pulmonary vascular resistance $(\Delta \mathrm{PVR}), \mathrm{c})$ change in cardiac index $(\Delta \mathrm{CI}), \mathrm{d})$ and change in right atrial pressure $(\Delta \mathrm{Pra})$.

degrees of haemodynamic changes, as well as different methods of evaluation of haemodynamic parameters. Thus, it cannot be excluded that an association may exist for responder patients and over a longer followup, as reported in nonrandomised studies or registries [45]. In addition, on treatment, haemodynamic changes are usually defined as the difference between baseline value and a snap-shot repeat evaluation under resting conditions and may, therefore, not be representative of the full haemodynamic benefit provided by therapies under daily life. In this regard, availability of implantable devices that provide a more comprehensive monitoring of haemodynamic changes may turn out to be valuable for risk stratification in $\mathrm{PAH}$ patients [46]. Thus, a definitive assessment of the cost-effectiveness of haemodynamic changes measurement in $\mathrm{PAH}$ patients cannot be made from the present analysis and deserve further exploration in prospective studies using different techniques [47].

\section{Study limitations}

Our study has some limitations. First, the analysis reported was based on aggregate rather than individual patient data. In addition, the current analysis does not allow us to exclude potential significant influence of the type of therapy on the association between haemodynamic effects and clinical events, and applies to the short follow-up of clinical trials. Thus, our findings cannot be generalised to long-term treatment of PAH. Furthermore, trials analysed included naive and already treated patients and, therefore, whether reported prognostic differences between naive and treated patients may have influenced our observations cannot be evaluated from our analysis [44]. Finally, since the technique used to measure cardiac index was not reported in several trials included in our meta-regression, an influence of the technique used, i.e. thermodilution or estimated or actual Fick method, on the association with clinical outcome cannot be excluded. Yet, there are also strengths of this analysis that are represented by the lack of publication bias and by the sensitivity analysis that confirmed that our findings were not influenced by several potential effect modifiers. 


\section{Conclusions}

In the short duration of clinical trials, drug therapy favourably affects pulmonary haemodynamic parameters, exercise capacity and clinical outcome in PAH patients. Pulmonary haemodynamic changes, reported in randomised clinical trials, correlate with exercise capacity but not with clinical events, emphasising the need to keep on searching for markers of disease modification in PAH patients.

\section{References}

1 Simonneau G, Robbins IM, Beghetti M, et al. Updated clinical classification of pulmonary hypertension. J Am Coll Cardiol 2009; 54: S43-S54.

2 Task Force for Diagnosis and Treatment of Pulmonary Hypertension of European Society of Cardiology (ESC), European Respiratory Society (ERS), International Society of Heart and Lung Transplantation (ISHLT), et al. Guidelines for the diagnosis and treatment of pulmonary hypertension. Eur Respir J 2009; 34: 1219-1263.

3 McLaughlin VV, Archer SL, Badesch DB, et al. ACCF/AHA 2009 expert consensus document on pulmonary hypertension a report of the American College of Cardiology Foundation Task Force on Expert Consensus Documents and the American Heart Association developed in collaboration with the American College of Chest Physicians; American Thoracic Society, Inc.; and the Pulmonary Hypertension Association. J Am Coll Cardiol 2009; 53: $1573-1619$.

4 Galiè N, Rubin LJ, Hoeper M, et al. Treatment of patients with mildly symptomatic pulmonary arterial hypertension with bosentan (EARLY study): a double-blind, randomised controlled trial. Lancet 2008; 371: 2093-2100.

5 Humbert M, Barst RJ, Robbins IM, et al. Combination of bosentan with epoprostenol in pulmonary arterial hypertension: BREATHE-2. Eur Respir J 2004; 24: 353-359.

6 McLaughlin VV, Oudiz RJ, Frost A, et al. Randomized study of adding inhaled iloprost to existing bosentan in pulmonary arterial hypertension. Am J Respir Crit Care Med 2006; 174: 1257-1263.

7 Oudiz RJ, Schilz RJ, Barst RJ, et al. Treprostinil, a prostacyclin analogue, in pulmonary arterial hypertension associated with connective tissue disease. Chest 2004; 126: 420-427.

8 Rubin LJ, Mendoza J, Hood M, et al. Treatment of primary pulmonary hypertension with continuous intravenous prostacyclin (epoprostenol). Results of a randomized trial. Ann Intern Med 1990; 112: 485-491.

9 Badesch DB, Tapson VF, McGoon MD, et al. Continuous intravenous epoprostenol for pulmonary hypertension due to the scleroderma spectrum of disease. A randomized, controlled trial. Ann Intern Med 2000; 132: 425-434.

10 Barst RJ, Rubin LJ, Long WA, et al. A comparison of continuous intravenous epoprostenol (prostacyclin) with conventional therapy for primary pulmonary hypertension. The Primary Pulmonary Hypertension Study Group. N Engl J Med 1996; 334: 296-302.

11 Barst RJ, McGoon M, McLaughlin V, et al. Beraprost therapy for pulmonary arterial hypertension. Beraprost therapy for pulmonary arterial hypertension. J Am Coll Cardiol 2003; 41: 2119-2125.

12 Barst RJ, Langleben D, Frost A, et al. Sitaxsentan therapy for pulmonary arterial hypertension. Am J Respir Crit Care Med 2004; 169: 441-447.

13 Galiè N, Humbert M, Vachiéry JL, et al. Effects of beraprost sodium, an oral prostacyclin analogue, in patients with pulmonary arterial hypertension: a randomized, double-blind, placebo-controlled trial. J Am Coll Cardiol 2002; 39: 1496-1502.

14 Galiè N, Ghofrani HA, Torbicki A, et al. Sildenafil citrate therapy for pulmonary arterial hypertension. $N$ Engl J Med 2005; 353: 2148-2157.

15 Ghofrani HA, Morrell NW, Hoeper MM, et al. Imatinib in pulmonary arterial hypertension patients with inadequate response to established therapy. Am J Respir Crit Care Med 2010; 182: 1171-1177.

16 Jing ZC, Yu ZX, Shen JY, et al. Vardenafil in pulmonary arterial hypertension: a randomized, double-blind, placebo-controlled study. Am J Respir Crit Care Med 2011; 183: 1723-1729.

17 Olschewski H, Simonneau G, Galiè N, et al. Inhaled iloprost for severe pulmonary hypertension. N Engl J Med 2002; 347: 322-329.

18 Simonneau G, Barst RJ, Galie N, et al. Continuous subcutaneous infusion of treprostinil, a prostacyclin analogue, in patients with pulmonary arterial hypertension: a double-blind, randomized, placebo-controlled trial. Am J Respir Crit Care Med 2002; 165: 800-804.

19 Simonneau G, Rubin LJ, Galiè N, et al. Addition of sildenafil to long-term intravenous epoprostenol therapy in patients with pulmonary arterial hypertension: a randomized trial. Ann Intern Med 2008; 149: 521-530.

20 Moher D, Liberati, A, Tetzlaff J, et al. Preferred Reporting Items for Systematic Reviews and Meta-Analyses: the PRISMA Statement. Ann Intern Med 2009; 151: 264-269.

21 Costanzo P, Perrone-Filardi P, Petretta M, et al. Calcium channel blockers and cardiovascular outcomes: a metaanalysis of 175,634 patients. J Hypertens 2009; 27: 1136-1151.

22 Detsky A, Naylor C, O'Rourke K, et al. Incorporating variations in the quality of individual randomized trials into meta-analysis. J Clin Epidemiol 1992; 45: 255-265.

23 Peters JL, Sutton AJ, Jones DR, et al. Comparison of two methods to detect publication bias in meta-analysis. JAMA 2006; 295: 676-680.

24 Sharp SJ. Meta-analysis regression. Stata Tech Bull 1998; 42: 16-22.

25 Costanzo P, Savarese G, Rosano G, et al. Left ventricular hypertrophy reduction and clinical events. A metaregression analysis of 14 studies in 12,809 hypertensive patients. Int J Cardiol 2012 [In press DOI: 10.1016/ j.ijcard.2012.06.084].

26 Thompson SG, Sharp SJ. Explaining heterogeneity in meta-analysis: a comparison of methods. Stat Med 1999; 18: 2693-2708.

27 Sharp S, Sterne J. Meta-analysis. Stata Tech Bull Reprints 1998; 7: 100-108.

28 Whitehead A. Meta-Analysis of Controlled Clinical Trials. Chichester, John Wiley \& Sons, 2002; p. 4.

29 Davies HT, Crombie IK, Tavakoli M. When can odds ratios mislead? Br Med J 1998; 316: 989-991.

30 McLaughlin VVMD, McGoon MD. Pulmonary Arterial Hypertension. Circulation 2006; 114: 1417-1431. 
31 Benza RL, Miller DP, Gomberg-Maitland M, et al. Predicting survival in pulmonary arterial hypertension: insights from the Registry to Evaluate Early and Long-Term Pulmonary Arterial Hypertension Disease Management (REVEAL). Circulation 2010; 122: 164-172.

32 D'Alonzo GE, Barst RJ, Ayres SM, et al. Survival in patients with primary pulmonary hypertension. Results from a national prospective registry. Ann Intern Med 1991; 115: 343-349.

33 Humbert M, Sitbon O, Chaouat A, et al. Survival in patients with idiopathic, familial, and anorexigen-associated pulmonary arterial hypertension in the modern management era. Circulation 2010; 122: 156-163.

34 Thenappan T, Shah SJ, Rich S, et al. Survival in pulmonary arterial hypertension: a reappraisal of the NIH risk stratification equation. Eur Respir J 2010; 35: 1079-1087.

35 Sitbon $\mathrm{O}$, Humbert $\mathrm{M}$, Nunes $\mathrm{H}$, et al. Long-term intravenous epoprostenol infusion in primary pulmonary hypertension: prognostic factors and survival. J Am Coll Cardiol 2002; 40: 780-788.

36 McLaughlin VV, Shillington A, Rich S. Survival in primary pulmonary hypertension: the impact of epoprostenol therapy. Circulation 2002; 106: 1477-1482.

37 Provencher S, Sitbon O, Humbert M, et al. Long-term outcome with first-line bosentan therapy in idiopathic pulmonary arterial hypertension. Eur Heart J 2006; 27: 589-595.

38 Benza RL, Gomberg-Maitland M, Naeije R, et al. Prognostic factors associated with increased survival in patients with pulmonary arterial hypertension treated with subcutaneous treprostinil in randomized, placebo-controlled trials. J Heart Lung Transplant 2011; 30: 982-989.

39 Nickel N, Golpon H, Greer M, et al. The prognostic impact of follow-up assessments in patients with idiopathic pulmonary arterial hypertension. Eur Respir J 2012; 39: 589-596.

40 van de Veerdonk MC, Kind T, Marcus JT, et al. Progressive right ventricular dysfunction in patients with pulmonary arterial hypertension responding to therapy. J Am Coll Cardiol 2011; 58: 2511-2519.

41 Girgis RE. Predicting long-term survival in pulmonary arterial hypertension: more than just pulmonary vascular resistance. J Am Coll Cardiol 2011; 58: 2520-2521.

42 Dellegrottaglie S, Perrone-Filardi P, García-Alvarez A, et al. Serial phase-contrast MRI for prediction of pulmonary hemodynamic changes in patients with pulmonary arterial hypertension. Int J Cardiol 2012; 157: 140-142.

43 Savarese G, Paolillo S, Costanzo P, et al. Do changes of 6-minute walk distance predict clinical events in patients with pulmonary arterial hypertension? J Am Coll Cardiol 2012; 60: 1192-1201.

44 Miller DP, Gomberg-Maitland M, Humbert M. Survivor bias and risk assessment. Eur Respir J 2012; 40: 530-532.

45 Gomberg-Maitland M, Dufton C, Oudiz RJ, et al. Compelling evidence of long-term outcomes in pulmonary arterial hypertension? A clinical perspective. J Am Coll Cardiol 2011; 57: 1053-1061.

46 Frantz RP. Hemodynamic monitoring in pulmonary arterial hypertension. Expert Rev Respir Med 2011; 5: 173-178.

47 Farber HW, Foreman AJ, Miller DP, et al. REVEAL Registry: correlation of right heart catheterization and echocardiography in patients with pulmonary arterial hypertension. Congest Heart Fail 2011; 17: 56-64. 